\title{
Can COSMOthermX Predict a Salting in Effect?
}

\author{
Martta Toivola ${ }^{\mathrm{a}}$, Nønne L. Prisle ${ }^{\mathrm{b}}$, Jonas Elm ${ }^{\mathrm{c}}$,
}

Eleanor M. Waxman ${ }^{\mathrm{d}}$, Rainer Volkamer ${ }^{\mathrm{e}}$, and Theo

\section{Kurtén*a}

\author{
${ }^{\mathrm{a}}$ Department of Chemistry, P.O. Box 55, FI-00014 University of Helsinki, Finland \\ ${ }^{\mathrm{b}}$ Nano and Molecular Systems Research Unit, University of Oulu, Finland, P. O. Box 3000, \\ FI-90014 University of Oulu, Finland \\ ${ }^{\mathrm{c}}$ Department of Physics, University of Helsinki, P.O. Box 64, FI-00014 University of Helsinki, \\ Finland \\ ${ }^{\mathrm{d}}$ Department of Chemistry and Biochemistry, University of Colorado Boulder, CO, USA, now at \\ Applied Physics Division, NIST, Boulder, CO, USA \\ ${ }^{\mathrm{e}}$ Department of Chemistry and Biochemistry \& CIRES, University of Colorado at Boulder, CO, \\ USA
}


ABSTRACT: We have used COSMO-RS, a method combining quantum chemistry with statistical thermodynamics, to compute Setschenow constants $\left(\mathrm{K}_{\mathrm{S}}\right)$ for a large array of organic solutes and salts. The studied systems comprise both atmospherically relevant organic solutes and salts, as well as aromatic species and tetraalkylaminium salts for which experimental data is available. In agreement with previous studies on single salts, the Setschenow constants predicted by COSMO-RS (as implemented in the COSMOThermX program) are generally too large compared to experimental values. COSMOThermX overpredicts the salting out effect (positive $\mathrm{K}_{\mathrm{S}}$ ), and/or underpredicts the salting in effect (negative $\mathrm{K}_{\mathrm{S}}$ ). For ammonium and sodium salts, $\mathrm{K}_{\mathrm{S}}$ values are larger for oxalates and sulfates, and smaller for chlorides and bromides. For chloride and bromide salts, $\mathrm{K}_{\mathrm{S}}$ values usually increase with decreasing size of the cation, along the series $\mathrm{Pr}_{4} \mathrm{~N}^{+}<\mathrm{Et}_{4} \mathrm{~N}^{+}<\mathrm{Me}_{4} \mathrm{~N}^{+} \leq \mathrm{Na}^{+} \approx \mathrm{NH}_{4}{ }^{+}$. Of the atmospherically relevant solute-salt systems studied, salting in is predicted only for oxalic acid in sodium and ammonium oxalate, as well as in sodium sulfate, solutions. COSMOThermX was thus unable to replicate the experimentally observed salting in of glyoxal (and/or its hydrates) in sulfate solutions, likely due to the overestimation of salting out effects. In contrast, COSMOThermX does qualitatively predict the experimentally observed salting in of multiple organic solutes in solutions of alkylaminium salts.

\section{INTRODUCTION}

The physical and chemical properties of secondary aerosol particles determine their ability to act as cloud condensation nuclei, which in turn affect cloud properties and thus the global climate. ${ }^{1}$ While sulfuric acid and nitrogen-containing bases may be required for the first steps of atmospheric new-particle formation, organic compounds in various states of oxidation 
dominate their growth processes, ${ }^{2}$ and have been observed to explain a remarkable part of the total aerosol mass. ${ }^{3}$ The partitioning of an organic compound between the gas phase and the aerosol particles depends on the solubility of the compound. Atmospheric aerosol particles may in general contain coexisting solid and liquid phases, and the latter may be either aqueous or organic. In this study, we focus on the solubility of organic compounds in the aqueous phase. Solvation of organic compounds plays a critical role in secondary organic aerosol formation ${ }^{4,5}$ and cloud droplet activation ${ }^{6}$ in the atmosphere. For example, Prisle et al. ${ }^{5}$ showed how SOA formation from uptake to an aqueous salt phase was much more modest than predicted from absorptive partitioning under the assumption of ideal (i.e. assuming that the activity of each component equals its mole fraction) aqueous phase mixing behavior of the organics. ${ }^{4}$ Bilde and Svenningsson $^{6}$ demonstrated how cloud droplet activation is significantly impacted by small amounts of salt altering the balance of droplet growth and organic aerosol solubility threshold in the aqueous droplet phase.

Atmospheric aerosol particles contain a mixture of both organic and inorganic components, and the aqueous aerosol phase may contain high concentrations of various ionic solutes, in particular salts such as sulfates, nitrates or chlorides. Due to non-ideality (nonvanishing mixing effects resulting from solute-solute or solute-solvent interactions), the solubility of organic molecules in such solutions may be very different from that in pure water. A decrease in the solubility of organics upon the addition of a salt is known as a salting out effect. Conversely, an increase in solubility is known as salting in. The change of solubility of neutral organic solutes in salt water can be described using the Setschenow relationship

$\log \left(\frac{S_{0}}{S}\right)=K_{S} \mathrm{c}_{S}$ 
where $S_{0}$ and $S$ are the solubilities of the solute in pure water and salt solution, respectively, and $c_{S}$ is the salt concentration (which can be expressed in terms of either molarities, moles of solute per liter of solution, or molalities, moles of solute per kilogram of solvent). Positive values of the Setschenow constant $\mathrm{K}_{\mathrm{S}}$ indicate a salting out effect, i.e. the salt lowers the solubility of the organics, while negative values indicate salting in. Equation 1 may be written also in terms of partition coefficients, as shown by Endo et al. ${ }^{7}$

Both experimental and theoretical studies on salting effects have been carried out. Experimentally, both salting in and salting out have been observed, with the latter tending to be more common for atmospherically relevant combinations of salts and organic solutes. $^{7,8,9,10,11,12,13,14}$ A possible explanation for this is that salting out is caused by a general competition for solvation between neutral organic and ionic solutes, while salting in is related to more specific favorable interactions between pairs of solutes (e.g. a neutral organic and a certain anion or cation). Currently available empirical models for predicting Setschenow constants are unable to simultaneously predict both salting in and salting out effects, possibly due to lacking descriptions of the specific favorable interactions behind salting in, or to the very different chemical characteristics between the molecules that salt in, and the molecules the empirical models are typically trained with. ${ }^{10,15,16,17}$

The combination of quantum chemistry - based modeling of molecular interactions with statistical thermodynamics offers a possibility to study equilibrium properties, such as salting effects, efficiently for large number of systems. The most advanced method of this type currently available is called COSMO-RS (The COnductor-like Screening Model for Real Solvents). ${ }^{18,19}$ COSMOtherm $\mathrm{X}^{20,21}$ is a commercial program based on the COSMO-RS method. Previous studies of Setschenow constants in $\left(\mathrm{NH}_{4}\right)_{2} \mathrm{SO}_{4}{ }^{10}$ and $\mathrm{NaCl}^{7}$ solutions show a moderately good 
correlation between experimental $\mathrm{K}_{\mathrm{S}}$ values and COSMOthermX predictions, but with a few outliers, notably caffeine in $\mathrm{NaCl}^{7}$

In this work we have calculated salt - solute - pair specific Setschenow constants for the following organic solutes: benzaldehyde, benzene, benzoic acid, 1,2-dimethylbenzene, 1,3dimethylbenzene, 1,4-dimethylbenzene, glycerol, glyoxal, glyoxal dihydrate, glyoxal monohydrate, 1,2-ISOPOOH (isoprene hydroxyl hydroperoxide), 3,4-ISOPOOH, isoprene epoxy diol, malonic acid, methylglyoxal dihydrate, 2-methyl tetraol, 1-naphthol, 2-naphthol, naphthalene, nitrobenzene, oxalic acid, phenol, succinic acid and toluene. These organic molecules are chosen for two reasons: they are either known or suggested to participate in atmospheric aerosol processes ${ }^{22},{ }^{23}$ or/and experimental salting constant values are available for them. $^{7,8,9,11,12,13}$ The selection of salt solutions is similarly motivated both by atmospheric relevance, and by the availability of experimental results. We have studied solutions of singly$\left(\mathrm{Cl}^{-}, \mathrm{Br}^{-}\right)$and doubly charged $\left(\mathrm{SO}_{4}{ }^{2-}, \mathrm{C}_{2} \mathrm{O}_{4}{ }^{2-}\right)$ anions with small singly charged cations $\left(\mathrm{Na}^{+}\right.$, $\mathrm{NH}_{4}{ }^{+}$). (In acidic solutions, $\mathrm{SO}_{4}{ }^{2-}, \mathrm{C}_{2} \mathrm{O}_{4}{ }^{2-}$ co-exist with their conjugate bases $\mathrm{HSO}_{4}{ }^{-}$and $\mathrm{HC}_{2} \mathrm{O}_{4}{ }^{-}$these were not included in the present study.) Additionally, we have studied the chloride and bromide salts of organic tetraalkylaminium cations: $\mathrm{Et}_{4} \mathrm{NCl}, \mathrm{Et}_{4} \mathrm{NBr}, \mathrm{Me}_{4} \mathrm{NCl}, \mathrm{Me}_{4} \mathrm{NBr}, \mathrm{Pr}_{4} \mathrm{NCl}$ and $\mathrm{Pr}_{4} \mathrm{NBr}$ (where $\mathrm{Me}=\mathrm{CH}_{3}, \mathrm{Et}=\mathrm{CH}_{3} \mathrm{CH}_{2}$, and $\mathrm{Pr}=\mathrm{CH}_{3} \mathrm{CH}_{2} \mathrm{CH}_{2}$ ). While experimental data is only available for some solute - salt pairs, we have here computed Setschenow constants for all combinations of the solutes and salts described above.

\section{METHODS}


We evaluated Setschenow constants using the COSMO-RS method, which is based on an electrostatic theory of locally interacting molecular surface descriptors and statistical thermodynamics. ${ }^{18}$ We used COSMOthermX version C30_1501. ${ }^{20,21}$ The advantage of this method is that no system-specific experimental parameters are needed (though when available these can be incorporated into some property calculations, and may improve the accuracy of results). ${ }^{24}$ The only pre-existing information needed for the modeling are the energetically favored structures (conformations) of the studied molecules. For flexible molecules, a representative set of conformations is needed (they are then treated in COSMOThermX using their Boltzmann-weighted populations). Accounting for multiple conformers is important mainly when the polarities of different conformers are very different, resulting in potentially large free energy differences between the gas phase and the aqueous phase. ${ }^{25}$ Thermodynamical properties of liquid systems are calculated from quantum chemistry-based molecular interactions.

The most time-consuming step of COSMO-RS modeling is creating the moleculespecific cosmo-files using density functional theory calculations. This step is done only once for each of the molecules in this study. The cosmo-files of molecules contain information on the screening charge distribution on a molecular conductor-like screening model surface, the $\sigma$ surface, and the energy. For benzene, phenol, nitrobenzene, toluene, benzaldehyde, benzoic acid, the dimethylbenzenes, naphthalene, $\mathrm{Na}^{+}, \mathrm{NH}_{4}{ }^{+}$and $\mathrm{Cl}^{-}$, the input files for the COSMOthermX calculations are taken from the library of the COSMOthermX program suite. (Note that all these systems have a very limited number of conformers - often only one.) For the other cases, conformer generation was first performed using the MMFF force-field, and the systematic conformer generation tool of the Spartan '14 program. ${ }^{26}$ When the total number of conformers was on the order of 100 or more (this was the case for 1,2-ISOPOOH, 3,4-ISOPOOH, $\operatorname{Pr}_{4} \mathrm{~N}^{+}$and 
$\mathrm{Et}_{4} \mathrm{~N}^{+}$), B3LYP/6-31+G(d) calculations were performed in Spartan on the MMFF structures, and a representative set of several tens of low-energy conformers was selected from these. For the ISOPOOH isomers with multiple possible intramolecular hydrogen bonds, several different hydrogen-bonding patterns were included in the conformer set, including also structures without intramolecular hydrogen bonds even when these were significantly higher in (gas-phase B3LYP/6-31+G(d)) energy.

The geometry optimizations were then performed in Turbomole ${ }^{27}$ at the BP-RIDFT/TZVP level (where BP refers to B88-VWN-P86). ${ }^{28}$ Gas phase single point-energies and cosmo-files were finally computed at the TZVPD-FINE level, which refers to BP-RIDFT/TZVPD, with the molecular surface cavity constructed using the fine grid marching tetrahedron algorithm. TZVPD-FINE is the highest-quality calculation method currently available for COSMO-RS simulations, and it is recommended especially for secondary and tertiary aliphatic amines and polyether compounds. ${ }^{24}$ For the flexible molecules, the TZVPDFINE and the subsequent COSMOThermX calculations were performed using the 20 lowest energy conformers optimized by Turbomole (at the BP-RI-DFT/TZVP level, with COSMO-RS solvation) for the neutral organics, and the 10 lowest for the cations. Test calculations on 3,4ISOPOOH indicates that our conformational sampling approach is sufficient for most of the systems studied here, but may severely underestimate the $\mathrm{K}_{\mathrm{S}}$ values for the ISOPOOH isomers with sulfate and oxalate salts.

\section{RESULTS AND DISCUSSION}


We evaluated the Setschenow constants using four different salt mole fractions (with respect to the total solution composition, i.e. moles of salt per moles of water and salt): 0.09, 0.009, 0.0009, and 0.00009. Solutions with a salt mole fraction of 0.009 were then studied in more detail. A salt mole fraction of 0.009 is approximately equivalent to a salt concentration of $0.5 \mathrm{~mol} / \mathrm{l}$, which is a typical seawater salt concentration, and also in line with the concentrations used by Endo et al. ${ }^{7}$ Salt concentrations in atmospheric aerosols and cloud droplets can be much higher or lower than this, depending especially on the size of the aerosol particle or droplet and ambient relative humidity.

The Setschenow constants obtained for the studied organic-salt-pairs in salt solution with a salt mole fraction of 0.009 are presented in Figure 1, with numerical values given in Table S1 of the Supporting Information. Setschenow constants are reported in units of inverse molality; $\mathrm{kg} / \mathrm{mol}$. The reason for using molality rather than molarity is that the former does not require knowledge of the exact liquid densities. The variation in the Setschenow constants depending on the salt concentration used in the calculations is illustrated using error bars in Figure S1 in the Supporting Information (with numerical values given in Tables S2-S4). For $80 \%$ of the systems, the variation in the Setschenow constant across the range of studied salt mole fractions is less than $0.2 \mathrm{~kg} / \mathrm{mol}$, and for $97 \%$ it is less than $0.3 \mathrm{~kg} / \mathrm{mol}$. These variations are not negligible given that the absolute values of the computed Setschenow constants are all between -0.6 and 1.0 $\mathrm{kg} / \mathrm{mol}$. In other words, the concentration dependence of the solubility predicted by COSMOThermX does not exactly match that of the original Setschenow equation.

The majority of the studied systems (solute - salt pairs) salt out, as expected from previous studies. ${ }^{7,8,11,12,13}$ COSMOThermX was unable to replicate the experimentally observed salting in of glyoxal (in practice, glyoxal hydrates) ${ }^{9}$ or succinic acid $^{29}$ in sulfate solutions. 
However, systems containing large organic cations, $\mathrm{Pr}_{4} \mathrm{~N}^{+}$or $\mathrm{Et}_{4} \mathrm{~N}^{+}$, are predicted to salt in most of the organics studied here. Also, oxalic acid is predicted by COSMOThermX to salt in into sodium and ammonium oxalate, as well as sodium sulfate solutions.

Some clear trends can also be discerned from the data. For the chloride and bromide salts, the $\mathrm{K}_{\mathrm{S}}$ values usually (with a few exceptions) increase along the cation series $\operatorname{Pr}_{4} \mathrm{~N}^{+}<\mathrm{Et}_{4} \mathrm{~N}^{+}<$ $\mathrm{Me}_{4} \mathrm{~N}^{+} \leq \mathrm{Na}^{+} \approx \mathrm{NH}_{4}{ }^{+}$. For the ammonium and sodium salts, $\mathrm{C}_{2} \mathrm{O}_{4}{ }^{2-}$ and $\mathrm{SO}_{4}{ }^{2-}$ anions salt out most organics more strongly than $\mathrm{Cl}^{-}$and $\mathrm{Br}^{-}$anions. Furthermore, the organics that salt in most strongly in $\operatorname{Pr}_{4} \mathrm{~N}^{+}$or $\mathrm{Et}_{4} \mathrm{~N}^{+}$- containing solutions also salt out most strongly in $\mathrm{C}_{2} \mathrm{O}_{4}{ }^{2-}$ and $\mathrm{SO}_{4}{ }^{2-}-$ containing solutions.

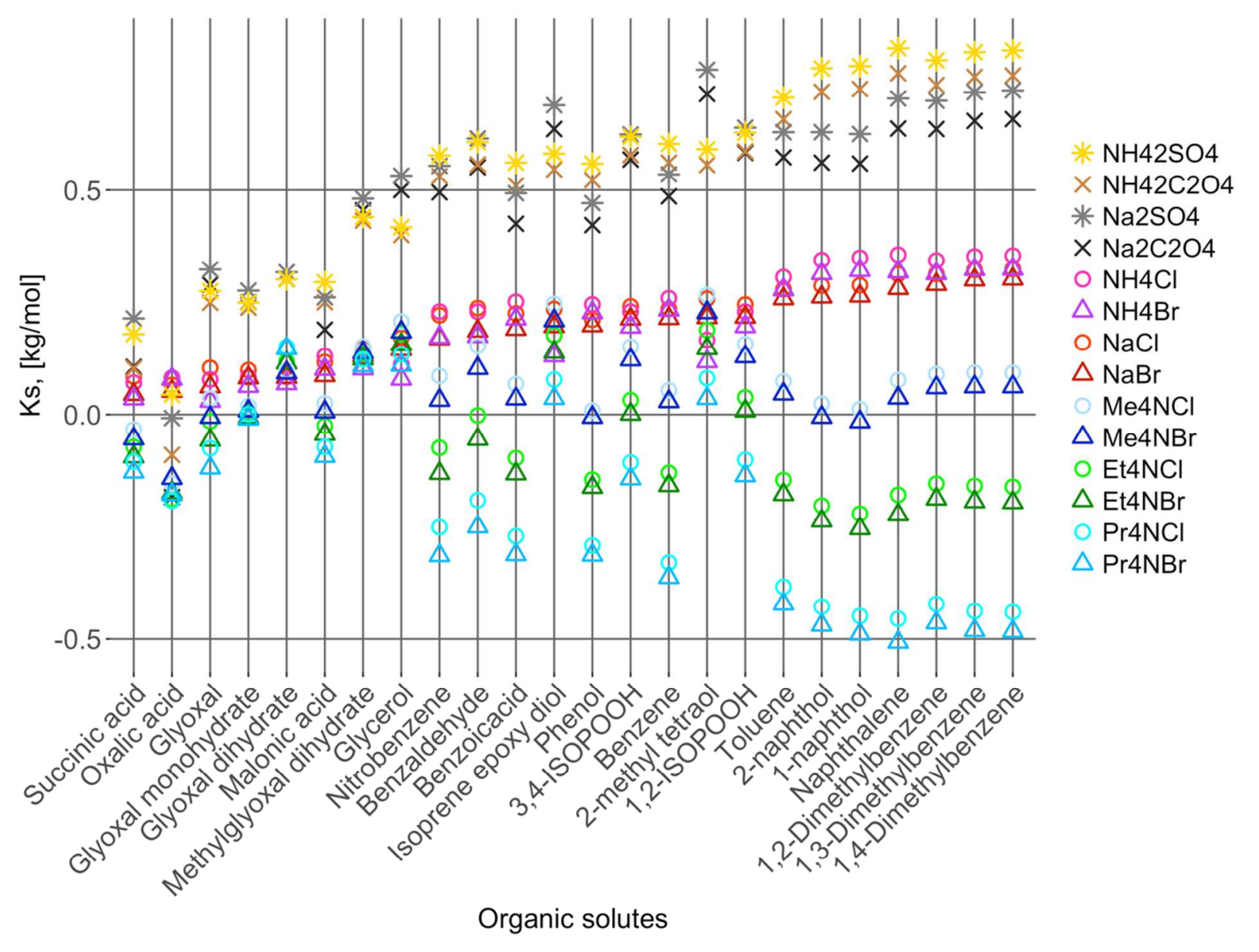


Figure 1. Values of the Setschenow constants at $25^{\circ} \mathrm{C}$ for the studied solute-salt-pairs, computed at a salt mole fraction of 0.009 .

Experimental values for Setschenow constants are reported either in units of $\mathrm{kg} / \mathrm{mole}$ (inverse molality), or in units of $1 / \mathrm{mol}$ (inverse molarity). Kampf et al. demonstrated that using molality rather than molarity gives a consistent picture of salting effects in both pure inorganic and mixed inorganic/organic aerosol seed particles. ${ }^{9}$ In other words, the Setschenow constants obtained for pure and mixed seed particles were found to be identical when using molality units, while the value of $\mathrm{K}_{\mathrm{S}}$ depended on the seed when using molarity units.

For a semi-quantitative comparison of COSMO-RS and experimental results, ${ }^{7,8,9,11,12,13}$ we here assume that the density of the salt solution is the unit density of pure water, $1 \mathrm{~kg} / \mathrm{l}$, and convert molarities into molalities using this density. Density variations of aqueous salt solutions are often unknown, and may be on the order of tens of percent. The resulting comparison is shown in Figure 2 (where only the Setschenow constants for which experimental values could be found are plotted).

COSMOthermX has previously been reported to overestimate the salting out effect in sodium chloride and ammonium sulfate solutions. ${ }^{7,10}$ Our calculations indicate that this observation applies also to other salt solutions. As seen from Figure 2, COSMOthermX generally gives an upper limit for $\mathrm{K}_{\mathrm{S}}$ - the experimental value is never significantly higher than the computed $\mathrm{K}_{\mathrm{S}}$, but is often significantly lower. Predictions for $\mathrm{Na}_{2} \mathrm{SO}_{4}, \mathrm{NaCl}$ and $\mathrm{NaBr}$ salts are in reasonable agreement with experiments, while the largest disagreements are found for some of the ammonium salts, and for $\mathrm{Pr}_{4} \mathrm{NBr}$ and $\mathrm{Et}_{4} \mathrm{NBr}$. This might indicate problems in the 
quantitative treatment of $\mathrm{NH}_{4}{ }^{+} \mathrm{H}$-bonds on one hand, and of the interactions of neutral organic solutes with the large alkylaminium cations on the other. The assumption of unit density may also be the most problematic for solutions containing the larger cations. Earlier studies on single salts ${ }^{7,9}$ have found that the predictive power of COSMOThermX can be improved by multiplying the computed $K_{S}$ values by a correction factor. For our dataset including multiple salts, we were unable to significantly improve the predictive power of COSMOThermX either by a constant offset or by a multiplicative factor. Fortunately, as seen from Figure 2, the sign of $\mathrm{K}_{\mathrm{S}}$ is correctly predicted for most cases, with a few cases of COSMOThermX predicting salting out while experiments indicate salting in, and no examples of the opposite misprediction.

The general overestimation of $\mathrm{K}_{\mathrm{S}}$ by COSMOThermX is likely the reason for the incorrect prediction of salting out for glyoxal hydrates in sulfate solutions. It can be seen from Figure 1 that the Setschenow constants for glyoxal hydrates in sulfate solutions $\left(\mathrm{Na}_{2} \mathrm{SO}_{4}\right.$ and $\left.\left(\mathrm{NH}_{4}\right)_{2} \mathrm{SO}_{4}\right)$ are lower than those of most other organic solutes. Thus, COSMOThermX may be able to predict the relative ordering of Setschenow constants (for the same solute in different salts, or for different solutes in the same salt) reasonably, despite the absolute values being overestimated. 


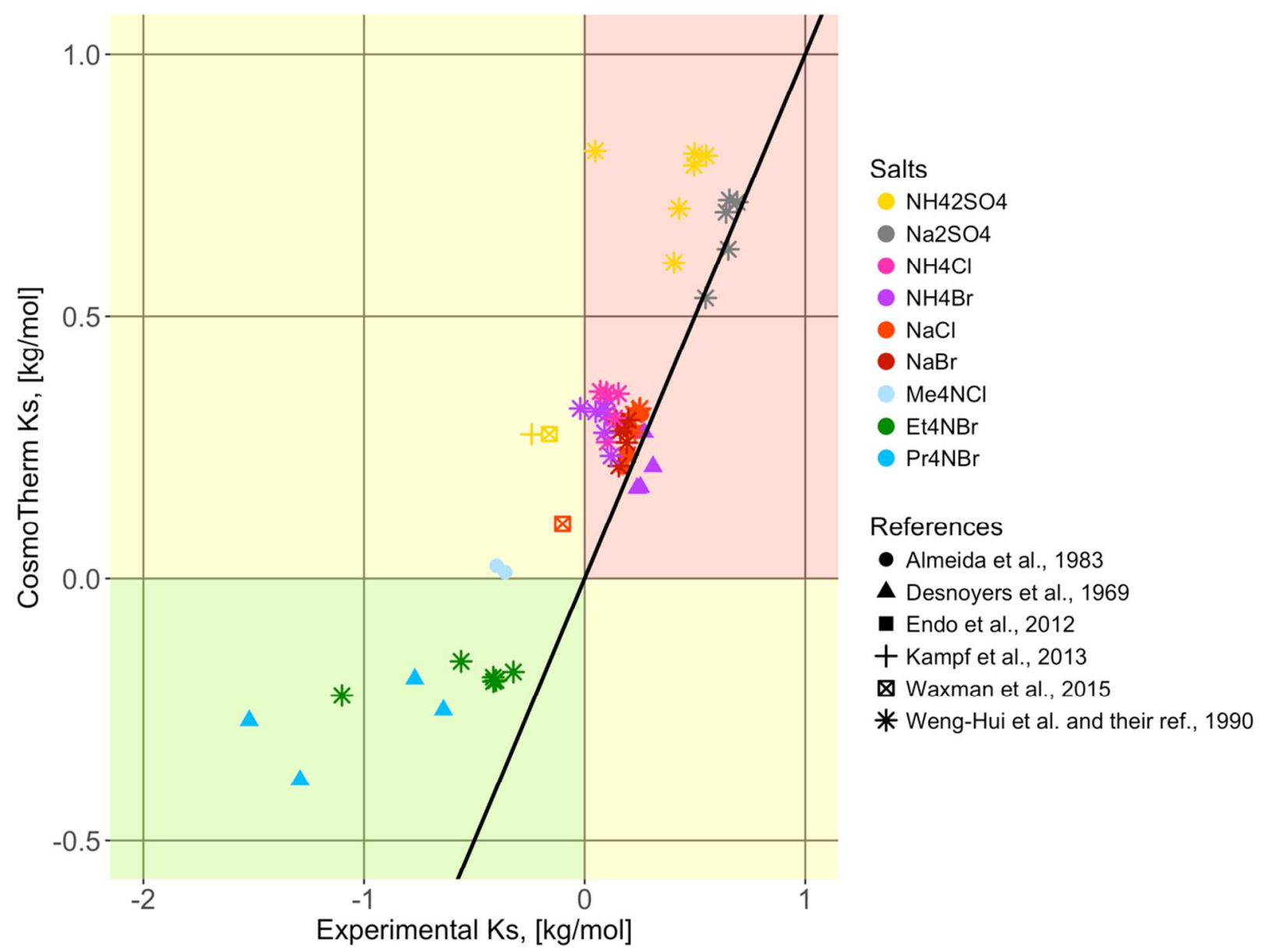

Figure 2. Setschenow constants predicted by COSMOTherm X (at $25^{\circ} \mathrm{C}$, computed at a salt mole fraction of 0.009) plotted against the experimental values (converted from molarities into molalities where necessary by assuming a unit density). The data points in the green shaded area correspond to systems for which both COSMOThermX and experiments yield salting in, while those in the red shaded area correspond to systems for which both yield salting out. The data points in the yellow shaded areas correspond to systems for which COSMOThermX and experiments disagree on the sign of $\mathrm{K}_{\mathrm{S}}$. Experimental data from Almeida et al., ${ }^{11}$ Desnoyers et al. ${ }^{12}$, Endo et al. ${ }^{7}$, Kampf et al. ${ }^{9}$, Waxman et al. ${ }^{8}$ and Weng-Hui et al. ${ }^{13}$ (and references therein). 
The molecular-level mechanisms behind salting in/out phenomena can be described in terms of changes in the environment of a solute molecule between pure water and a salt solution. Endo et al. ${ }^{7}$ explained the salting out effect by an increase in the cohesion energy of water when salt was added. This would then weaken the interaction of the organic solute with the water, and increase the work of cavity creation, leading to decreased solubility. This explanation can be connected to the structural effects on water of different ions, especially anions: structure-making "kosmotropes" have been suggested to salt neutral solutes out, ${ }^{30}$ while structure-breaking "chaotropes" could salt them in. If this structural effect were the main or sole interaction behind salting effects, salting in or out should depend mainly on the salt, with the identity of the neutral organic solute playing little or no role. Clearly, this is not the case either experimentally (Figure 2) or according to our modeling (Figure 1): the degree and even the sign of the salting effect depends almost as much on the neutral solute as on the salt. For example, our results indicate that alkylaminium salts may cause either strong salting in (e.g. for dimethylbenzenes) or moderate salting out (e.g. for the glyoxal hydrates), while oxalate salts may cause either strong salting out (e.g. for aromatics), or weak salting in (for oxalates). Furthermore, both the predicted and the experimentally observed salting effects disagree with the predictions from the "structure" theory of ions. According to the classification in the review article by Marcus, ${ }^{31} \operatorname{Pr}_{4} \mathrm{~N}^{+}$is a structuremaking ion, $\mathrm{Na}^{+}$and $\mathrm{Et}_{4} \mathrm{~N}^{+}$are borderline cases, and all the other ions in our study are structurebreaking. Yet by far the strongest salting-in effects are seen (both theoretically and experimentally) for the structure-making $\operatorname{Pr}_{4} \mathrm{~N}^{+}$salts, while the strongest salting-out effects are seen (again both theoretically and experimentally) for sulfate salts, which according to Marcus ${ }^{31}$ should be structure-breaking. Salting, and especially salting in, must therefore involve specific 
interactions between the neutral and ionic solutes - as acknowledged even in studies generally subscribing to the kosmotrope/chaotrope - analysis of salting phenomena. ${ }^{30}$

The COSMO-RS method is based on pairwise interacting surface charges, and intermolecular interactions are determined by the probability distributions of the screening charges ( $\sigma$-profiles) of the individual molecules embedded in a virtual conductor. The $\sigma$-profile is computed separately for each individual molecule. COSMOThermX then treats interactions between all the different components of a system (in our cases consisting of water, a cation, an anion, and an organic solute). Thus, both direct interactions between neutral and ionic solutes, as well as indirect water-mediated interactions, are modelled.

Comparison of the $\sigma$-profiles of two molecules or ions can be used to visualize their possible interactions. For example, Schröder et al. ${ }^{16}$ studied the salting effect of hexafluorobenzene in several salt solutions. They found that a salting out effect was observed when no interactions between the organic solute and water molecules could be identified from the $\sigma$-profiles. Conversely, salting in is associated with complementary parts in the $\sigma$-profiles of solute and solvent molecules, indicating attractive interactions. (Two $\sigma$-profiles peaks are "complementary" when they are located at opposite sides of the origin, at approximately equal distances from it.) In our study, the organics that clearly salt in into $\operatorname{Pr}_{4} \mathrm{~N}^{+}$salt solutions $\left(\mathrm{K}_{\mathrm{s}}<-0,1\right)$ are characterized by $\sigma$-profiles that are relative narrow, and have a probability peak that is complementary with the $\sigma$-profile for $\operatorname{Pr}_{4} \mathrm{~N}^{+}$. Conversely, the $\sigma$-profiles of these organics are not at all complementary with those of the dianions (sulfate and oxalate), leading to large salting out in their solutions. This explains the large spread between different salts of the $\mathrm{K}_{\mathrm{S}}$ values for the compounds on the right-hand side of Figure 1. 
$\sigma$-profiles for the solvent water molecule and for the ionic solutes driving salting in/out of the neutral organic are shown in Figure 3. Profiles for the organic solutes themselves are not shown for simplicity. $\sigma$-profiles for two representative organic solutes (napthalene and oxalic acid) are shown in Figure S2 in the Supporting Information (and additional $\sigma$-profiles can be visualized from the cosmo files provided in a separate zip archive in the Supporting Information). The order of $\mathrm{K}_{\mathrm{s}}$ values for organic solutes with $\mathrm{NH}_{4}{ }^{+}$and $\mathrm{Na}^{+}$salts with different anions follows the order of the $\sigma$-profile peaks of the anions, as shown in Figure $3\left(\mathrm{Br}-\mathrm{Cl}-\mathrm{C}_{2} \mathrm{O}_{4}-\right.$ $\mathrm{SO}_{4}$ ). In other words, the more polar anions, with $\sigma$-profile peaks further from the origin, cause greater salting out. This is in agreement with recent experimental observations by Wang et al. ${ }^{14}$, who report stronger salting out for a large variety of organic solutes in sodium and ammonium sulfate salts than in sodium and ammonium chloride (or nitrate) salts. For cations, the $\sigma$-profiles of $\operatorname{Pr}_{4} \mathrm{~N}^{+}, \mathrm{Et}_{4} \mathrm{~N}^{+}$and $\mathrm{Me}_{4} \mathrm{~N}^{+}$are wider and closer to the origin compared to those of $\mathrm{NH}_{4}^{+}$and $\mathrm{Na}^{+}$, and they partly complement the $\sigma$-profiles of weakly polar or non-polar organic molecules (not shown), leading in some cases to salting in as shown in Figure 1.

$\mathrm{NH}_{4}{ }^{+}$may form a hydrogen bond with the oxygen atom of a water molecule, which increases the cohesion energy as suggested by Endo et al., ${ }^{7}$ and could lead to stronger salting out for $\mathrm{NH}_{4}^{+}$salts than for the corresponding $\mathrm{Na}^{+}$salts. This pattern is predicted for many of the organic solutes studied here, though the differences between sodium and ammonium salts with the same anion are generally small. However, the recent measurements by Wang et al. ${ }^{14}$ report the opposite trend, with sodium sulfate and chloride salting out all the organic solutes in their study more strongly than ammonium sulfate and chloride, respectively. COSMOThermX predicts stronger salting out for sodium sulfate and oxalate salts compared to ammonium sulfate and oxalate salts for the following organic solutes: glycerol, glyoxal, glyoxal dihydrate, glyoxal 
monohydrate, isoprene epoxy diol, methylglyoxal dihydrate and 2-methyl tetraol. These organic solutes are all able to act as $\mathrm{H}$-bond acceptors, forming $\mathrm{H}$-bonds with both water and $\mathrm{NH}_{4}{ }^{+}$. This may lead to relatively weaker salting out of these organic solutes by ammonium oxalate and sulfate compared to sodium oxalate and sulfate. However, the COSMOThermX predictions disagree with experimental observations ${ }^{8}$ for methylglyoxal hydrates, for which salting out has been found to be stronger for $\mathrm{NH}_{4}^{+}$salts than for $\mathrm{Na}^{+}$salts.

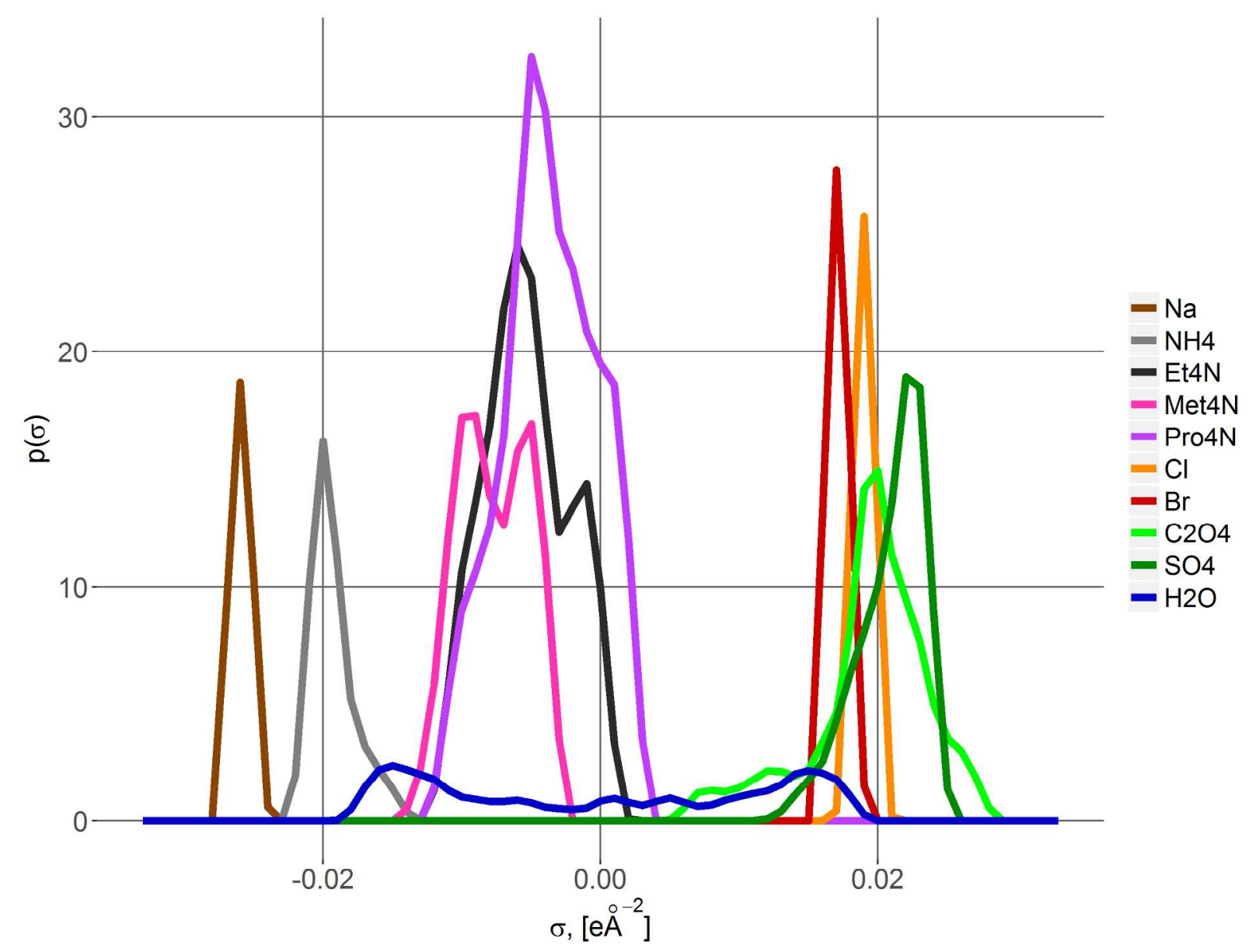

Figure 3. $\sigma$-profiles for the water molecule and for the various ions included in this study 
Oxalic acid is an interesting exception among the studied organics. It is the only molecule for which COSMOThermX predicts salting in also by salts composed only of small inorganic ions. While oxalic acid can in principle act as both an H-bond acceptor and an H-bond donor, the latter characteristic is dominant (as usual for acids), and oxalic acid therefore interacts favorably with strong $\mathrm{H}$-bond acceptors such as $\mathrm{C}_{2} \mathrm{O}_{4}{ }^{2-}$ and $\mathrm{SO}_{4}{ }^{2-}$ anions. This leads to salting in by $\mathrm{Na}^{+}$salts of these anions. The reason for larger Setschenow constants (greater salting out / lesser salting in) of oxalic acid in $\mathrm{NH}_{4}{ }^{+}$solutions $\left(\left(\mathrm{NH}_{4}\right)_{2} \mathrm{SO}_{4},\left(\mathrm{NH}_{4}\right)_{2} \mathrm{C}_{2} \mathrm{O}_{4}\right)$ might be a result of stronger interactions between $\mathrm{NH}_{4}{ }^{+}$and water molecules, which tends to favor salting out as discussed above. Strong hydrogen bonding between glyoxal hydrates and the sulfate anion were suggested by Kurtén et al. ${ }^{32}$ as the reason for the experimentally observed ${ }^{8,9}$ salting in of glyoxal in sulfate solutions. While COSMOThermX was unable to predict the experimentally observed behavior for glyoxal (in practice, its hydrates), the negative $\mathrm{K}_{\mathrm{S}}$ predicted for oxalic acid in some sulfate and oxalate solutions indicates that the general mechanism of salting in due to strong specific hydrogen bonds between an organic solute and a dianion is at least qualitatively described by the COSMO-RS method.

We further compared the computed $\mathrm{K}_{\mathrm{S}}$ values with the three different interaction energy components reported by COSMOThermX for each of the neutral organic molecules: the misfit energy, the H-bond energy and the van der Waals (vdW) energy. While the main interaction partner for the neutral organic molecules is likely (in all but the most concentrated salt solutions) the solvent water, salting effects are related to differences in the interactions of neutral solutes between pure water and salt solutions. In other words, the absolute magnitude of the solute water interaction is largely irrelevant to the salting phenomenon, as only differences in interactions matter. We thus plotted the $\mathrm{K}_{\mathrm{S}}$ values against the differences in each interaction 
energy component between the pure water and the salt solution (at a salt mole fraction of 0.009). These differences contain contributions from both direct interactions between neutral organic and ionic solutes, as well as water-mediated interactions such as differences in the work of cavity creation.

The misfit energy E(misfit) is a measure of the energy cost of embedding the molecule in a real solution instead of a perfect conductor continuum, ${ }^{19}$ and differences in the misfit energy between pure water and a salt solution are thus at least qualitatively related to the effect of the salt on the work of cavity creation around the neutral solute. Figure 4 shows a linear relationship between the calculated $\mathrm{K}_{\mathrm{S}}$ values and the difference in misfit energies between pure water and the salt solution $\left(\Delta \mathrm{E}\right.$ (misfit)). However, the correlation is quite weak in $\mathrm{Et}_{4} \mathrm{NBr}, \mathrm{Na}_{2} \mathrm{C}_{2} \mathrm{O}_{4}$ and $\mathrm{Na}_{2} \mathrm{SO}_{4}$ solutions. An organic molecule salts in if its misfit energy in salt solution is lower, or just slightly higher, than in the water solution. In contrast, a large Setschenow constant (strong salting out) indicates a high misfit energy in salt solution. Somewhat surprisingly, clear correlations between the Setschenow constants of all the studied systems and the H-bond or vdW-energy differences were not observed (see Figures 5 and 6). However, the predicted Setschenow constants for the carbonate and sulfate salts, which form strong hydrogen bonds, do correlate weakly with the H-bond energy difference (see Figure 5). Similarly, the predicted Setschenow constants for the alkylaminium salts, which interact with neutral organic solutes mainly via van der Waals forces, correlate weakly with the vdW - energy difference (see Figure $6)$.

Especially for atmospherically relevant solute-salt combinations, salting out seems to be the general rule, and salting in the exception. This can be understood in terms of the mechanisms discussed by both Schröder et al. ${ }^{16}$ and Endo et $a l^{7}{ }^{7}$ small anions and cations tend to interact 
strongly with solvent water molecules, and thus by default decrease the solubility of neutral organics - unless some strong and specific favorable interactions of the neutral solute counteracts this effect. The general increase in Setschenow constants along the series $\operatorname{Pr}_{4} \mathrm{~N}^{+}<$ $\mathrm{Et}_{4} \mathrm{~N}^{+}<\mathrm{Me}_{4} \mathrm{~N}^{+} \leq \mathrm{Na}^{+} \approx \mathrm{NH}_{4}^{+}$reflects the strength of the favorable interaction between the cations and water: the smaller and more polar cations interact more strongly with water molecules, leading (on average) to greater salting out of neutral organic solutes. The analogous increase in the Setschenow constants in $\mathrm{NH}_{4}^{+}$and $\mathrm{Na}^{+}$salts along the anion series $\mathrm{Br}^{-}<\mathrm{Cl}^{-}<$ $\mathrm{C}_{2} \mathrm{O}_{4}{ }^{2-}<\mathrm{SO}_{4}{ }^{2-}$ is another example of the same mechanism: more polar (smaller or more highly charged) anions cause stronger salting out.

The salting in encountered in the systems studied here can be divided into two subgroups, corresponding to two very different types of attractive interactions: that of a large, hydrophobic (typically aromatic) molecule with a large alkylaminium cation, and that of a small, extremely polar hydrogen-bond donor with a doubly charged anion (sulfate or oxalate). As illustrated in Figure 1 and Table S1, COSMOThermX is in principle able to describe both of these types of salting in, which have also been observed in the literature. The data in Figures 5 and 6 also support the hypothesis that van der Waals interactions between the organic solute and the alkylaminium cations drive salting in in the former case, while hydrogen bonding between the organic solute and the dianion drives salting in in the latter case. However, the latter type of salting in is predicted only for oxalate, likely related to the general overestimation of $\mathrm{K}_{\mathrm{S}}$.

COSMOThermX has recently been suggested to overestimate the effect of intramolecular hydrogen bonds on vapor pressures of conformationally flexible polyfunctional molecules. ${ }^{33} \mathrm{~A}$ similar overestimation of the strengths of the hydrogen bonds between water molecules and anions and/or cations, relative to those between the organic solutes and dianions, could be a 
possible explanation for the misprediction of $\mathrm{K}_{\mathrm{S}}$ for example for glyoxal hydrates in sulfate solutions. However, this mechanism would not explain the overestimation of $\mathrm{K}_{\mathrm{S}}$ observed also for solutes without hydrogen-bonding groups.

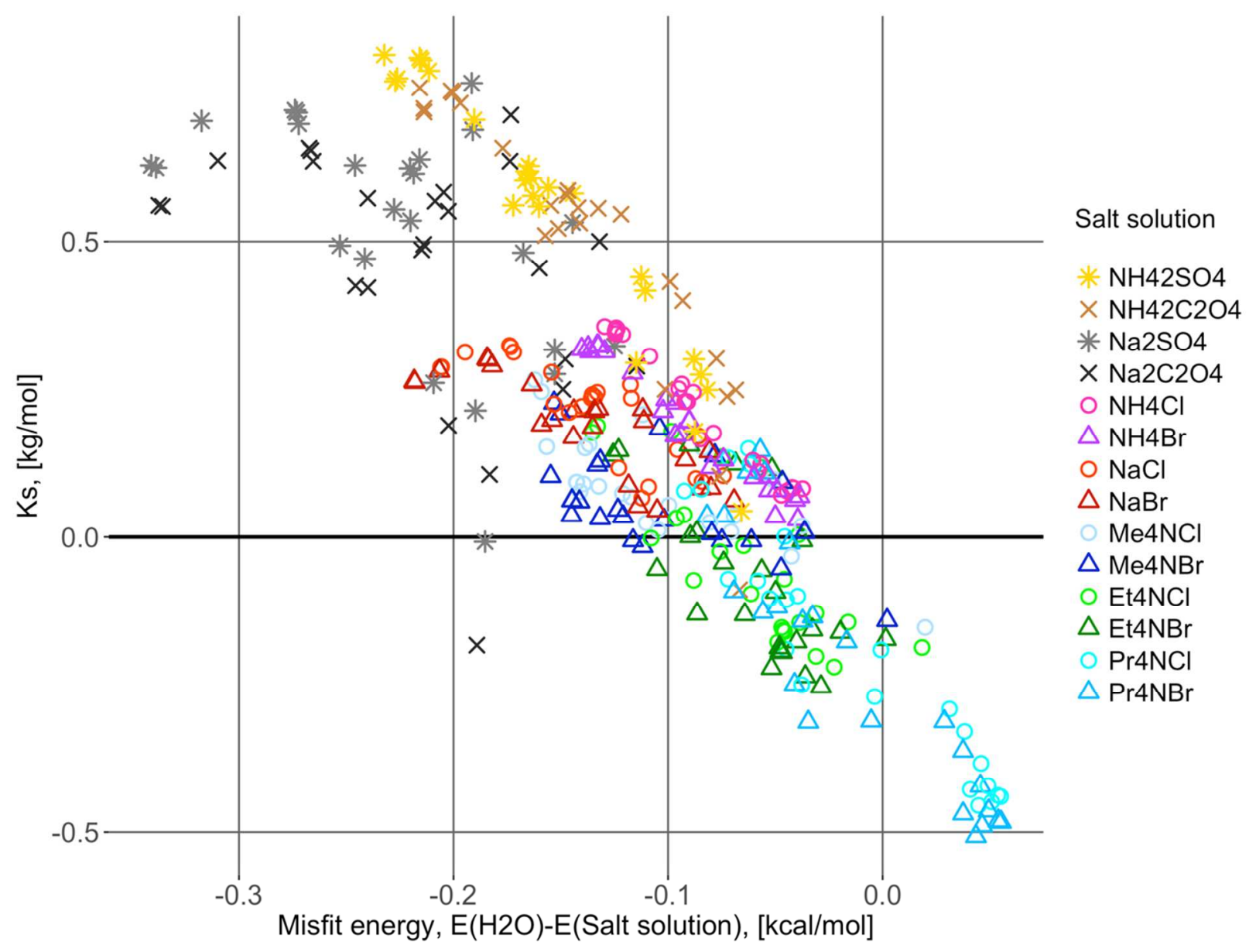

Figure 4. Setschenow constants plotted as a function of the difference in misfit energies between pure water and the salt solution, at $25 \mathrm{C}$ and using a salt mole fraction of 0.009 . 


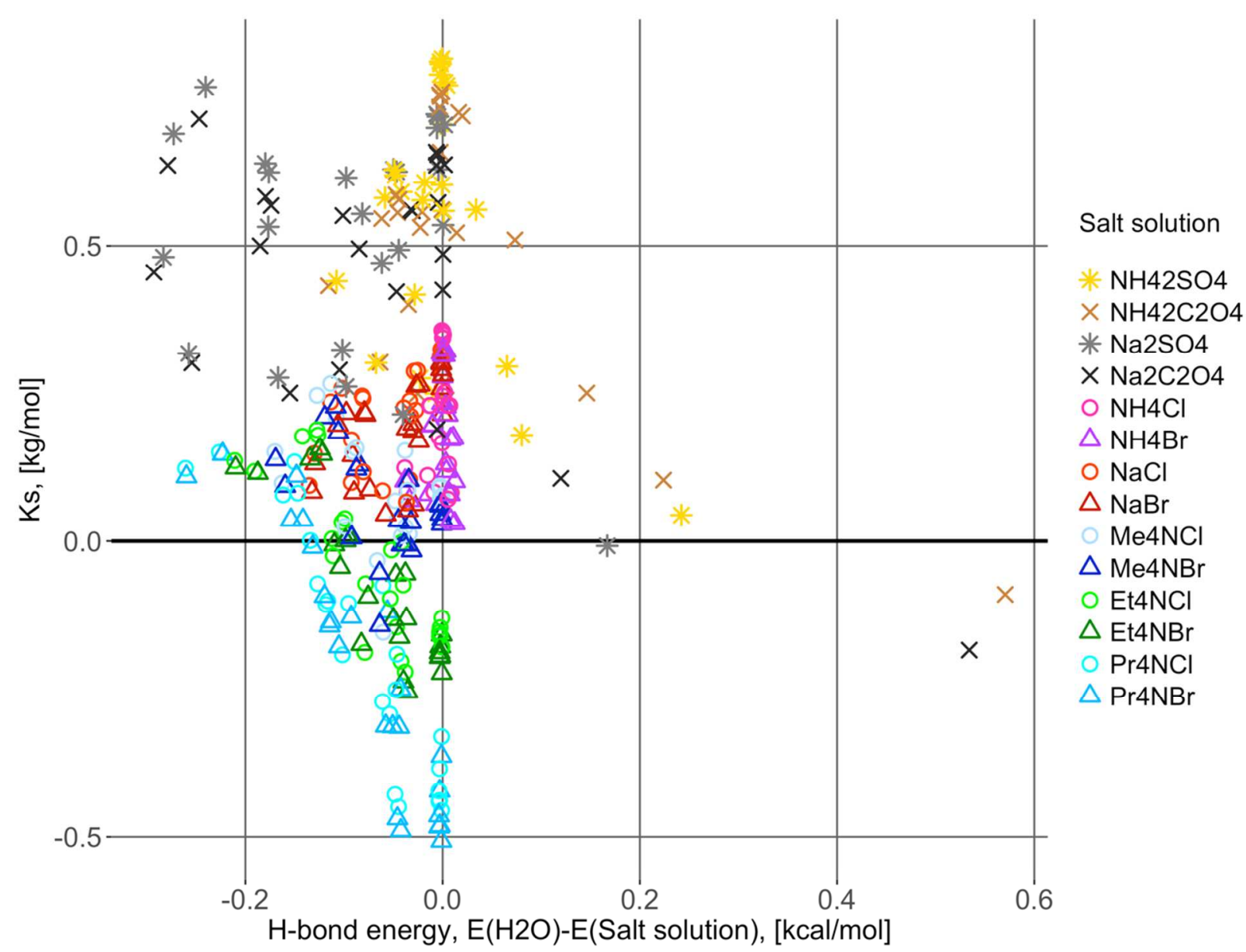

Figure 5. Setschenow constants plotted as a function of the difference in H-bond energies between pure water and the salt solution, at $25^{\circ} \mathrm{C}$ and using a salt mole fraction of 0.009 . 


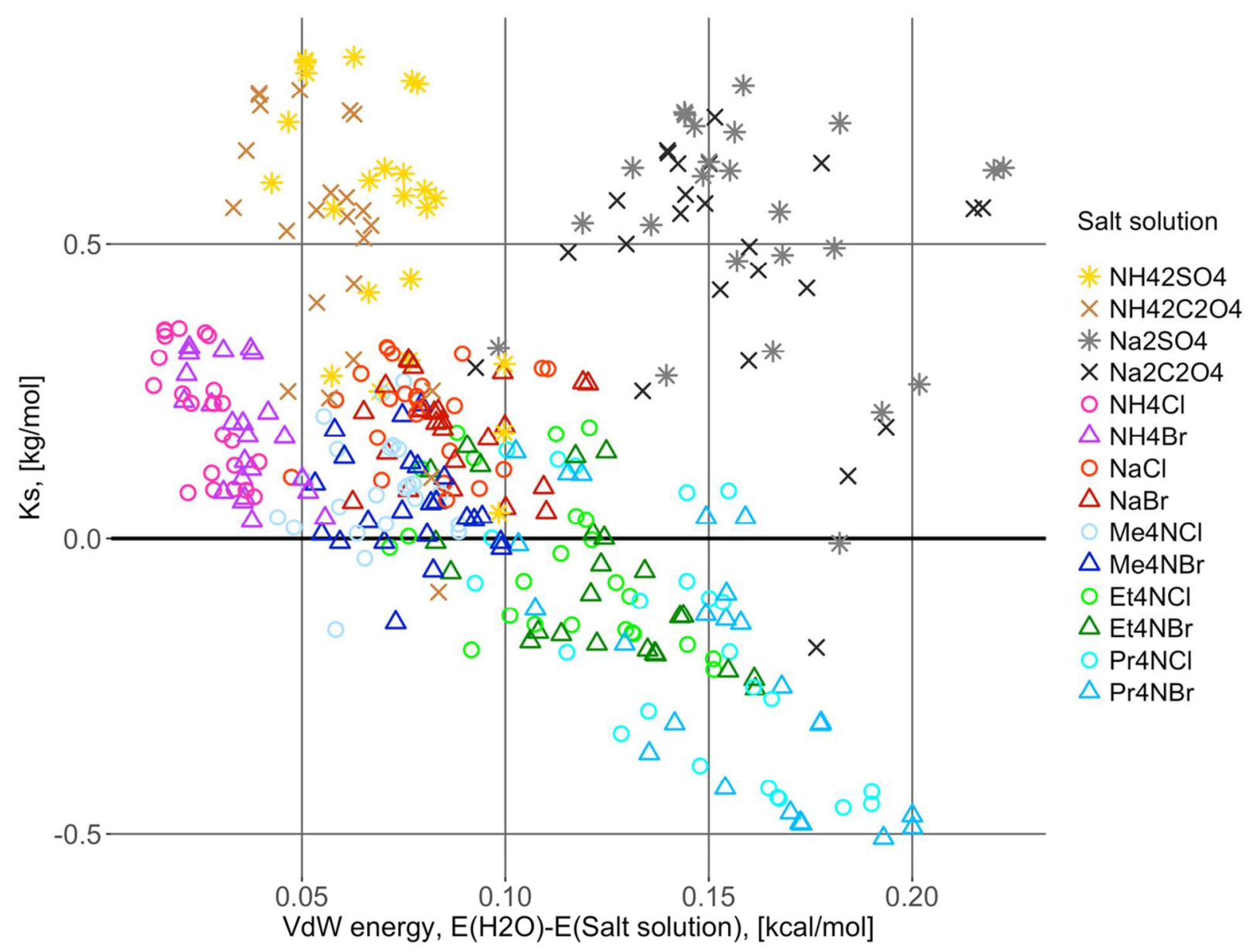

Figure 6. Setschenow constants plotted as a function of the difference in van der Waals energies between pure water and the salt solution, at $25 \mathrm{C}$ and using a salt mole fraction of 0.009 .

\section{CONCLUSIONS}

We have computed Setschenow constants for a large set of organic solute-salt pairs, containing both atmospherically relevant compounds and salts, as well as systems for which salting in has been experimentally observed. Qualitatively, COSMOThermX is able to predict salting in (negative Setschenow constants) for two very different types of systems: large aromatic molecules with salts containing large alkylaminium cations, and small polar H-bond 
donors with salts containing doubly charged anions (sulfate and oxalate). However, Setschenow constants are almost always overestimated by COSMOThermX (by up to $1.5 \mathrm{~kg} / \mathrm{mol}$ for some aromatics in alkylaminium salts), possibly due to an overestimation of the relative strength of the general interactions leading to salting out (e.g. competition for solvent molecules) compared to the more specific favorable interactions between neutral solutes and ions which are responsible for salting in. For example, we speculate that COSMOThermX may overestimate the relative strengths of the hydrogen bonds between water and dianions compared to those between polar organics and dianions. For this reason, the only atmospherically relevant compound for which COSMOThermX is able to predict salting in is oxalic acid - e.g. the behavior of glyoxal in sulfate solutions in incorrectly predicted. We suggest that COSMOThermX can nevertheless be used to evaluate relative Setschenow constants of different solutes in the same salt, or the same solute in different salts. Furthermore, despite the exact drivers behind the overestimate being unclear, the systematic nature of the errors in the predicted $K_{S}$ mean that COSMOThermX can be used as a quick qualitative test for salting in: if COSMOThermX predicts a negative Setschenow constant for a given system, then it is very likely to display (significant) salting in. Similarly, large positive Setschenow constants likely indicate an absence of salting in, though they should not necessarily be taken as an indication of strong salting out. The ability to at least qualitatively predict salting effects using a relatively simple computational tool such as COSMOthermX represents a great advantage for atmospheric aerosol systems, which typically comprise water, salt, and a vast amount of different organic solute. It is virtually impossible to perform systematic experimental analysis for all the possible composition combinations of such aerosol systems. There is a need to better understand the drivers for the observed bias in 
predicting $\mathrm{K}_{\mathrm{S}}$ in order to more quantitatively complement experimental data and fill the gaps in atmospheric models.

\title{
ASSOCIATED CONTENT \\ Supporting Information. Tables S1-S4. Setschenow constants computed using salt mole fraction of $0.009,0.09,0.0009$ and 0.00009 , respectively. Figure S1. Dependence of the Setschenow constants on the salt mole fraction. Figure S2. $\sigma$-profiles for the lowest-energy conformers of naphthalene, oxalic acid, $\mathrm{Pr}_{4} \mathrm{~N}^{+}$and $\mathrm{C}_{2} \mathrm{O}_{4}{ }^{2-}$. (PDF) .cosmo and .energy files for all structures not found in the COSMOThermX library. (ZIP)
}

\section{AUTHOR INFORMATION}

Corresponding Author

Theo Kurtén

Department of Chemistry, University of Helsinki, P.O. Box 55, FI-00014 University of Helsinki, Finland theo.kurten@helsinki.fi

\begin{abstract}
Author Contributions
The manuscript was written through contributions of all authors. All authors have given approval to the final version of the manuscript.
\end{abstract}




\section{ACKNOWLEDGMENT}

We thank prof. Ilona Riipinen for helpful discussions, and Noora Hyttinen for help with test calculations. We thank the Academy of Finland for funding and the CSC IT Center for Science for computer time. This project has received funding from the European Research Council (ERC) under the European Union's Horizon 2020 research and innovation programme (grant agreement No 717022), and U.S. National Science Foundation (AGS1649147). E.W. is recipient of a NRC fellowship. J. E. thanks the Carlsberg Foundation for financial support.

\section{REFERENCES}

${ }^{1}$ Stocker, T. F.; Quin, D.; Plattner, G.-K.; Tignor, M. M. B.; Allen, S. K.; Boschung, J.; Nauels, A.; Xia, X.; Bex, V.; Midgley, P. M. (eds). Climate Change 2013: The Physical Science Basis. Working Group I Contribution to the Fifth Assessment Report of the Intergovernmental Panel on Climate Change. Cambridge University Press: New York, U.S.A., 2013.

${ }^{2}$ Tröstl, J.; Chuang, W. K.; Gordon, H.; Heinritzi, M.; Yan, C.; Molteni, U.; Ahlm, L.; Frege, C.; Bianchi, F.; Wagner, R.; et al. The role of low-volatility organic compounds in initial particle growth in the atmosphere. Nature 2016, 533, 527-531.

${ }^{3}$ Jimenez, J. L.; Canagaratna, M.R.; Donahue, N. M.; Prevot, A. S. H.; Zhang, Q.; Kroll, J. H.; DeCarlo, P. F.; Allan, J. D.; Coe, H.; Ng, N. L.; et al. Evolution of Organic Aerosols in the Atmosphere. Science 2009, 326, 1525-1529.

${ }^{4}$ Pankow, J. F.; Chang, E. I. Variation in the Sensitivity of Predicted Levels of Atmospheric 
Organic Particulate Matter (OPM). Environ. Sci. Technol. 2008, 42, 7321-7329.

${ }^{5}$ Prisle, N. L.; Engelhart, G. J.; Bilde, M.; Donahue, N. M. Humidity influence on gas-particle phase partitioning of $\alpha$-pinene $+\mathrm{O}_{3}$ secondary organic aerosol. Geophys. Res. Let. 2010, 37 , L01802.

${ }^{6}$ Bilde, M.; Svenningsson, B. CCN activation of slightly soluble organics: the importance of small amounts of inorganic salt and particle phase. Tellus 2004, 56B, 128-134.

${ }^{7}$ Endo, S.; Pfennigsdorff, A.; Goss, K.-U. Salting-Out Effect in Aqueous NaCl Solutions: Trends with Size and Polarity of Solute Molecules. Environ. Sci. Technol. 2012, 46, 1496-1503.

${ }^{8}$ Waxman, E. M.; Elm, J.; Kurtén, T.; Mikkelsen, K. V.; Ziemann, P. J.; Volkamer R. Glyoxal and Methylglyoxal Setschenow Salting Constants in Sulfate, Nitrate, and Chloride Solutions: Measurements and Gibbs Energies. Environ Sci. Technol. 2015, 49, 11500-11908.

9 Kampf, C. J.; Waxman, E. M.; Slowik, J. G.; Dommen, J.; Pfaffenberger, L.; Praplan, A. P.; Prévôt, A. S. H.; Baltensperger, U.; Hoffmann, T.; Volkamer, R. Effective Henry’s Law Partitioning and the Salting Constant of Glyoxal in Aerosols Containing Sulfate Environ. Sci. Technol. 2013, 47, 4236-4244.

${ }^{10}$ Wang, C.; Duan Lei, Y.; Endo, S.; Wania, F. Measuring and Modeling the Salting-out Effect in Ammonium Sulfate Solutions. Environ. Sci. Technol. 2014, 48, 13238-13245.

11 Almeida, M. B.; Alvarez, A. M.; De Miguela, E. M.; Del Hoyo, S.E. Setschenow Coefficients for Naphthols by Distribution Method. Can. J. Chem. 1983, 61, 244. 
${ }^{12}$ Desnoyers, J. E.; Ichhaporia, D. F. M. Salting-In and Salting-Out of Polar Nonelectrolytes. Can. J. Chem. 1969, 47, 4639-.

${ }^{13}$ Wen-Hui, X.; Jing-Zhe. S.; Xi-Ming, X. Studies on the Activity Coefficient of Benzene and its Derivatives in Aqueous Salt Solutions. Thermochimica Acta 1990, 169 271-286.

${ }^{14}$ Wang, C.; Lei, Y. D.; Wania, F. The Effect of Sodium Sulfate, Ammonium Chloride, Ammonium Nitrate and Salt Mixtures on Aqueous Phase Partitioning of Organic Compounds. Environ. Sci. Technol. 2016, 50, 12742-12749.

${ }^{15}$ Wang, C.; Goss, K.-U.; Duan Lei, Y.; Abbatt, J. P. D.; Wania, F. Calculating Equilibrium Phase Distribution During the Formation of Secondary Organic Aerosol Using COSMOthermX. Environ. Sci. Technol. 2015, 49, 8585-8594.

${ }^{16}$ Schröder, B.; Freire, M. G.; Varanda F. R.; Marrucho, I. M.; Santos, L. M.; Coutinho, J. A. Aqueous solubility, effects of salts on aqueous solubility, and partitioning behavior of hexafluorobenzene: Experimental results and COSMO-RS predictions. Chemosphere 2011, 84, $415-422$.

\footnotetext{
${ }^{17}$ Wania, F.; Lei, Y. D.; Wang, C.; Abbatt, J. P. D.; Goss, K.-U. Novel methods for predicting gas-particle partitioning during the formation of secondary organic aerosol. Atmos. Chem. Phys. 2014, 14, 13189-13204.
}

\footnotetext{
${ }^{18}$ Klamt, A.; Schüürmann, G. J. COSMO: a new approach to dielectric screening in solvents with explicit expressions for the screening energy and its gradient. J. Chem. Soc., Perkin Trans. 1993, 3, 799-805.
} 
19 Klamt, A. Conductor-like Screening Model for Real Solvents: A New Approach to the Quantitative Calculation of Solvation Phenomena. J. Phys. Chem. 1995, 99, 2224-2235.
${ }^{20}$ Eckert, F.; Klamt, A. Fast solvent screening via quantum chemistry: COSMO-RS approach. AIChE Journal 2002 48, 369-385.

${ }^{21}$ Eckert, F.; Klamt, A. COSMOthermX, Version C3.0, Release 15.01; COSMOlogic GmbH \& Co. KG, Leverkusen, Germany, 2014.

${ }^{22}$ Bilde, M.; Barsanti, K.; Booth, M.; Cappa, C. D.; Donahue, N. M.; Emanuelsson, E. U.; McFiggans, G.; Krieger, U. K.; Marcolli, C.; Topping, D.; et al. Saturation Vapor Pressures and Transition Enthalpies of Low-Volatility Organic Molecules of Atmospheric Relevance: from Dicarboxylic Acids to Complex Mixtures. Chem. Rev. 2015, 115, 4115-4156.

${ }^{23}$ St Clair, J. M.; Rivera-Rios, J. C.; Crounse, J. D.; Knap, H. C.; Bates, K. H.; Teng, A. T.; Jørgensen, S.; Kjaergaard, H.G.; Keutsch, F.N.; Wennberg P. O. Kinetics and Products of the Reaction of the First-Generation Isoprene Hydroxy Hydroperoxide (ISOPOOH) with OH. $J$. Phys. Chem. A 2016, 120, 1441-1451.

\footnotetext{
${ }^{24}$ Klamt, A.; Eckert, F.; Arlt, W. COSMO-RS: an alternative to simulation for calculating thermodynamic properties of liquid mixtures. Annu. Rev. Chem. Biomol. Eng. 2010, 1, 101-22.

${ }^{25}$ Eckert, F. COSMOTherm reference manual; Cosmologic GmbH: 2015. Available online at: http://www.cosmologic.de/files/ downloads/manuals/COSMOTherm_Manual.pdf.

${ }^{26}$ Spartan'14; Wavefunction Inc: Irvine CA, 2014.
} 
27 TURBOMOLE V7.0 2015, a development of University of Karlsruhe and Forschungszentrum Karlsruhe GmbH, 1989-2007, TURBOMOLE GmbH, since 2007; available from http://www.turbomole.com.

\section{${ }^{28}$ Schäfer, A.; Klamt, A.; Sattel, D.; Lohrenz, J. C. W.; Eckert, F. COSMO implementation in TURBOMOLE: Extension of an efficient quantum chemical code towards liquid systems. Phys.} Chem. Chem. Phys. 2000, 2, 2187-.

${ }^{29}$ Yli-Juuti, T.; Zardini, A. A.; Eriksson, A.C.; Hansen, A. M. K.; Pagels, J. H.; Swietlicki, E.; Svenningsson, B.; Glasius, M.; Worsnop, D. R.; Riipinen, I.; et al. Volatility of Organic Aerosol: Evaporation of Ammonium Sulfate/Succinic Acid Aqueous Solution Droplets. Environ. Sci. Technol. 2013, 47, 12123-12130.

30 Zhang, Y.; Furyk, S.; Bergbreiter, D. E.; Cremer, P. S. Specific Ion Effects on the Water Solubility of Macromolecules: PNIPAM and the Hofmeister Series. J. Am. Chem. Soc. 2005, $127,14505-14510$.

\footnotetext{
${ }^{31}$ Marcus, Y. Effect of Ions on the Structure of Water: Structure Making and Breaking. Chem. Rev. 2009, 109, 1346-1370

32 Kurtén, T.; Elm, J.; Prisle, N. L.; Mikkelsen, K. V.; Kampf, C. J.; Waxman, E. M.; Volkamer, R. Computational Study of the Effect of Glyoxal-Sulfate Clustering on the Henry's Law Coefficient of Glyoxal. J. Phys. Chem. A 2015, 119, 4509-4514.
} 
${ }^{33}$ Kurtén, T.; Tiusanen, K.; Roldin, P.; Rissanen, M.; Luy, J.-N.; Boy, M.; Ehn, M.; Donahue, N. M. $\alpha$-Pinene Autoxidation Products May Not Have Extremely Low Saturation Vapor Pressures Despite High O:C Ratios. J. Phys. Chem. A 2016, 120, 2569-2582.

\section{TOC IMAGE}

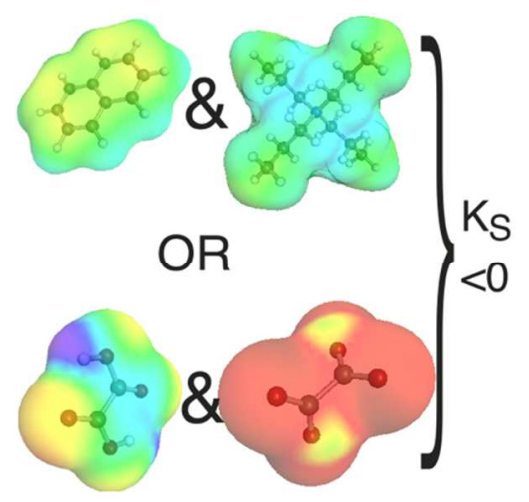




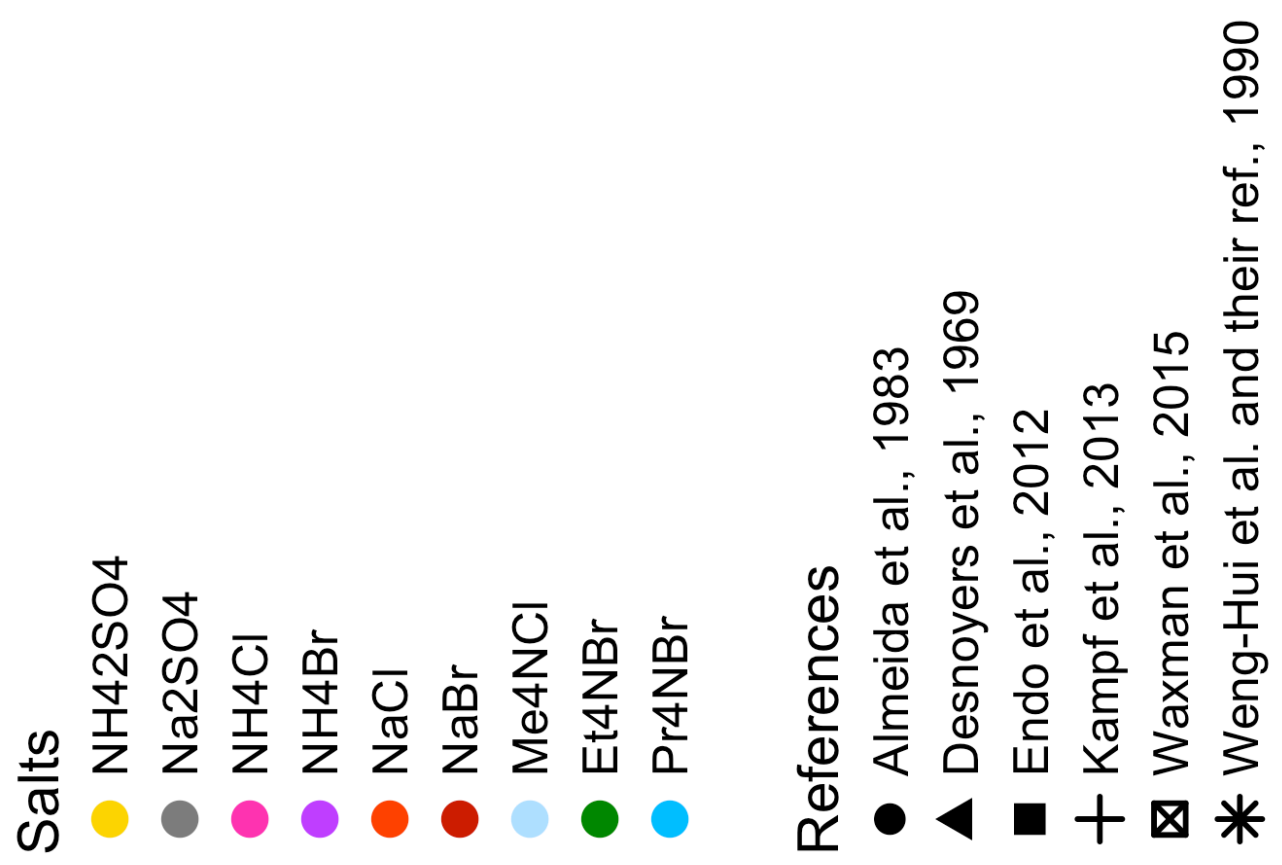
.

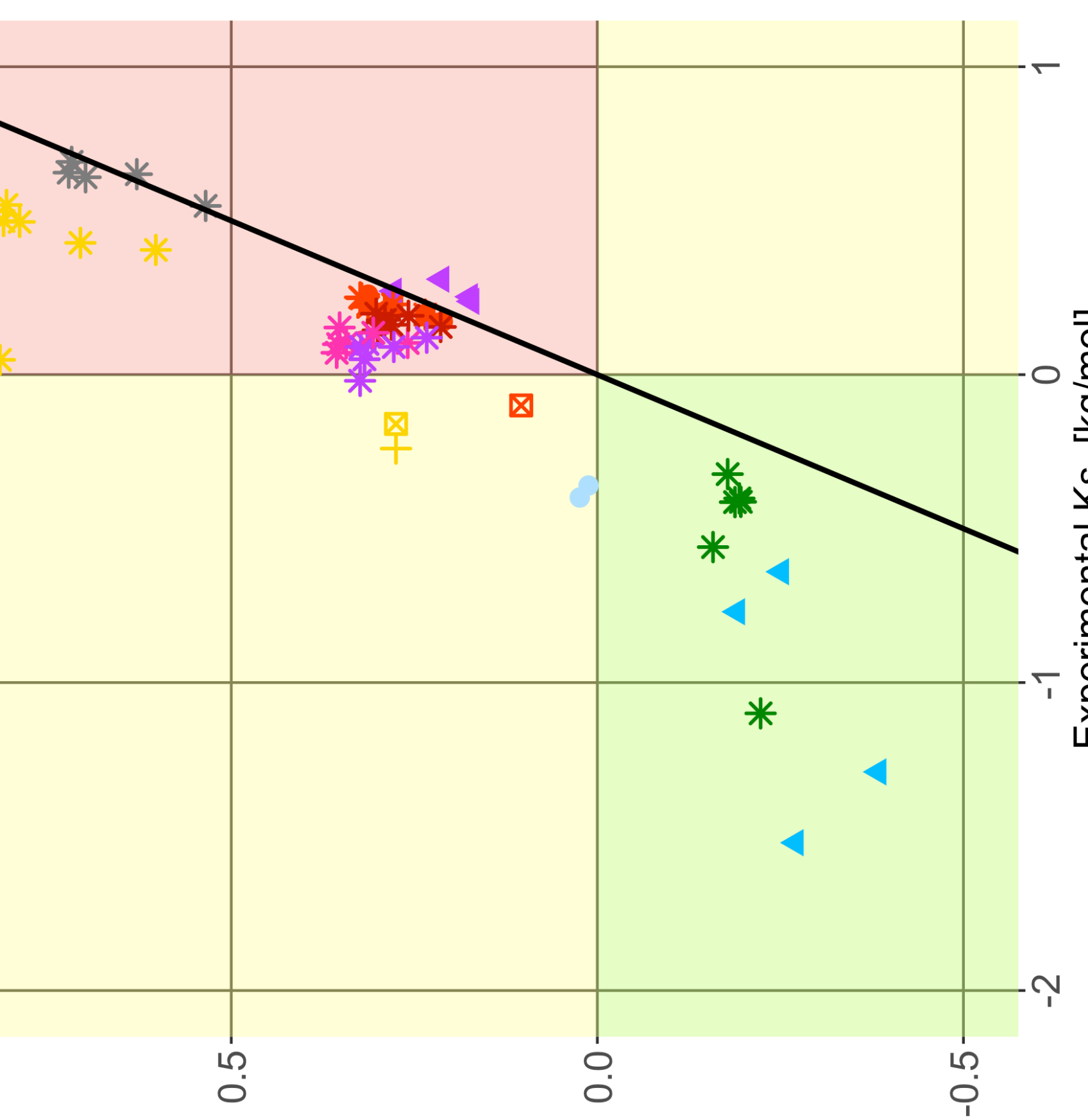

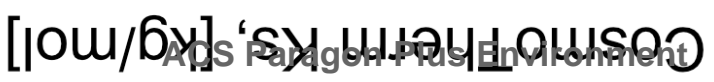



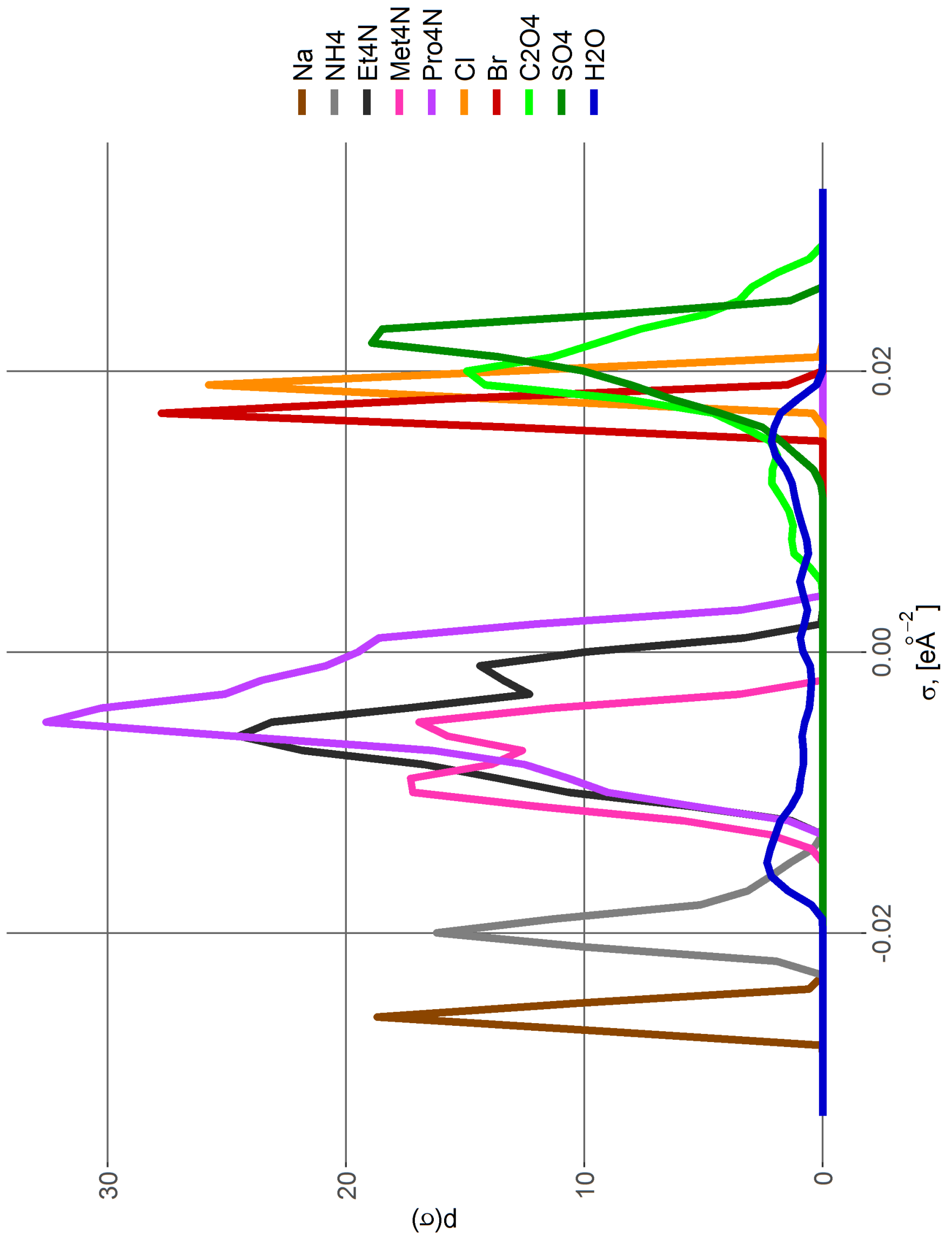


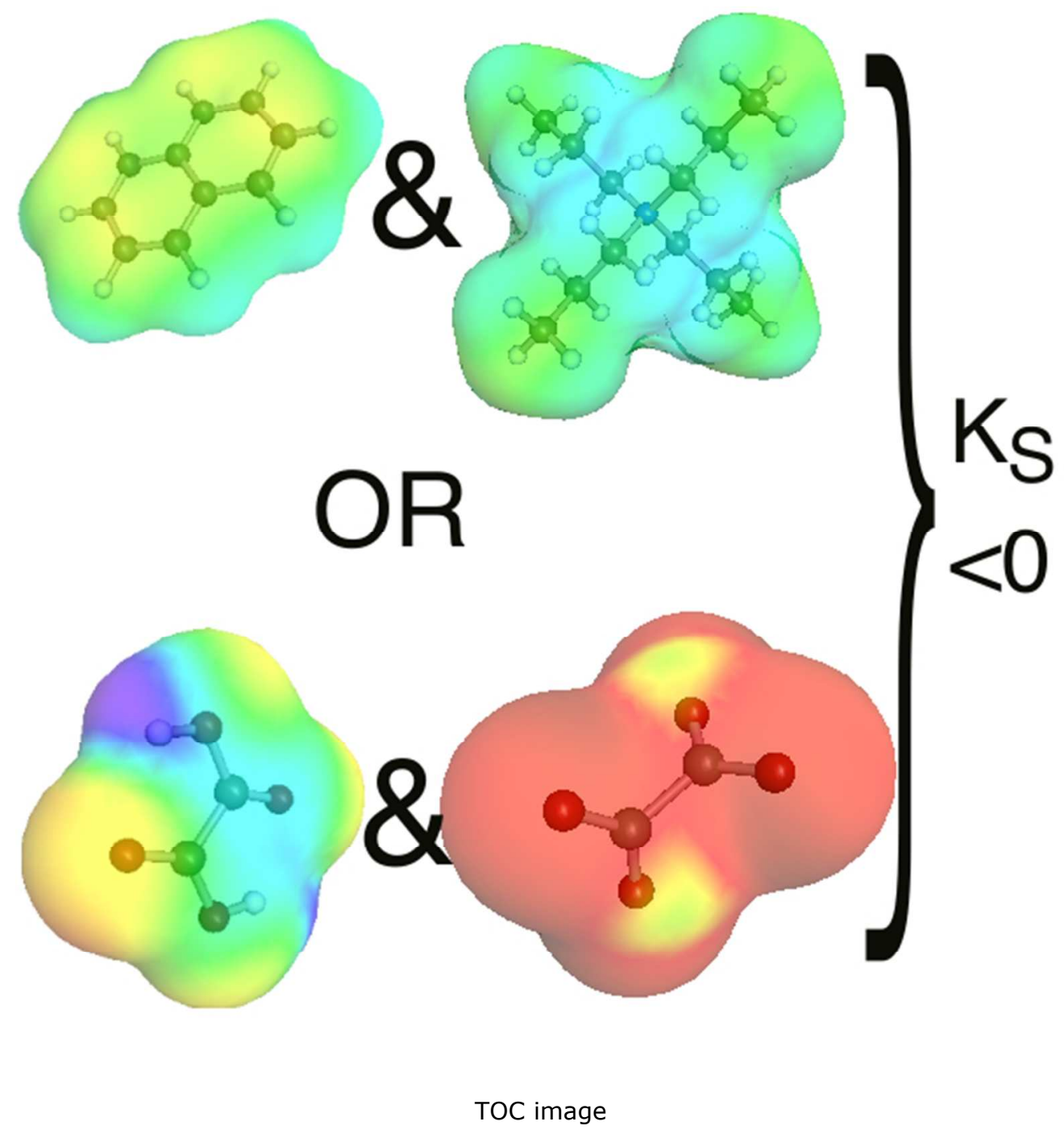

$50 \times 50 \mathrm{~mm}(300 \times 300$ DPI $)$ 